\title{
Impact of Electronic Health Records on the Hospital Bed Occupancy Rates in Surgical Units in France: Results from the E-SI (PREPS-SIPS) Study
}

\author{
By Morgane Plantier* \\ Nathalie Havet' \\ Nicolas Caquot \\ Pierre Biron \\ Camille Amaz. \\ Thierry Durand \\ Irène Philip" \\ Lionel Perrier"
}

The aim of this study was to evaluate the impact of electronic health records (EHRs) on the acute care hospital bed occupancy rates in surgical units across France. This retrospective study was based on information from four national databases. Several multivariate linear models were used to estimate the occupancy rates of surgical inpatient beds (model 1-1bis) and surgical outpatient beds (model 2-2bis), which were the dependent variables in our models. The independent variables were the hospital characteristics. In model 1, the higher the number of EHRs used compared with no EHRs, the higher the occupation rates of surgical inpatient beds $(p=0.002)$. In model 2, the higher the number of care units using EHRs, the higher the occupancy rates of surgical outpatient beds $(p=0.024)$. These data demonstrate the potential benefits of EHRs in acute care hospitals with regards to the surgical bed occupancy rates in France.

Keywords: Econometric, Government Policy, Hospital, Information System

\section{Introduction}

Health information technology (HIT) ${ }^{1}$ has the potential to improve hospital efficiency. It is particularly relevant in areas where health resources are limited. Indeed, because hospitals consume between 50 and $80 \%$ of public sector resources (Donald et al. 2000), it is crucial to improve their efficiency, which has also been recommended by the World Health Organization (WHO, 2010). Some experts believe that HIT integration is a pre-condition for more

\footnotetext{
${ }^{*}$ MPhil Student, University of Lyon, Cancer Centre Léon Bérard, France.

${ }^{\dagger}$ Associate Professor, University of Lyon, France.

* Finance Director, Cancer Centre Léon Bérard, France.

- Clinician, Cancer Centre Léon Bérard, France.

- Statistician, Cancer Centre Léon Bérard, France.

* Director, Cancer Centre Léon Bérard, France.

` Director, Cancer Centre Léon Bérard, France.

"Manager, Cancer Centre Léon Bérard, France.

${ }^{1}$ Health information technology (HIT) refers to the different processes that characterize the information system in health, e.g., computerized provider order entry (CPOE), electronic health records (EHRs), decision support systems (DSs), and health information system (HIS).
} 
effective hospital systems (Michelsen et al. 2015). As a result, many countries have intensified their implementation of this technology (Nguyen et al. 2014). For example, in France, the French Ministry of Health (DGOS) recently launched the national "Hôpital numérique 2012-2017" program, a strategic development plan for the modernization of HIT $^{1}$.

This growth in the use of HIT can be attributed to the increased number of studies that have shown its positive effects. O'Reilly et al. (2012) found that HIT offers cost benefits despite necessary upfront and ongoing investments. Meyer and Degoulet (2008) demonstrated the positive return in HIT investment using econometric approaches. Hillestad et al. (2005) concluded that the implementation of electronic health records (EHRs) was a cost-saving strategy. Moreover, EHRs improve the clinical quality of care (Jarvis et al. 2013). More generally, Jamal et al. (2009) found that HIT improved the quality of care. Chaudhry et al. (2006) hypothesized that this positive impact on the quality of care occurred through three main effects: increased adherence to guidelinebased care, enhanced surveillance and monitoring, and decreased medication errors. The improvement in efficiency results from a decrease in the length of hospital stays and time taken for administrative tasks (Hillestad et al. 2005), or a decrease in the utilization of care (Chaudhry et al. 2006).

Positive effects of HIT are widely acknowledged and encourage the implementation of these technologies. However, because the initial investments can be large, more empirical and robust results about the associated benefits of HIT are required to justify these upfront costs. The majority of qualitative and quantitative studies are based on subjective data (e.g. questionnaires); only a few are based on objective data (Nguyen et al. 2014). Another issue with previous studies is that many were limited to one hospital; only a few studies have included multiple settings (Bassi et al. 2013). Black et al. (2011) identified a "gap between the postulated and empirically demonstrated benefits of eHealth technologies" and showed that the majority of studies on HIT concentrated only on its impacts on quality and safety of health care.

To extend the quantitative and empirical results, we conducted a large study to evaluate the impact of implementation of EHRs and HIT on hospital performances. The objective of this multi-center study was to elucidate the effect of HIT, including adoption of EHRs, on the bed occupancy rates in surgical units in French hospitals.

\section{Materials and Methods}

\section{Study Design}

This retrospective, cross-sectional study was based on information from four national databases: oSIS (observatoire des Systèmes d'Information de Santé), IPAQSS (Indicateurs Pour l'Amélioration de la Qualité et la Sécurité

\footnotetext{
${ }^{1}$ The development and modernization plan using HIT aims to set objectives for six years: http://goo.gl/9hpmCk.
} 
des Soins), Hospi-Diag (French hospital performance indicators), and the national accreditation database. The French Ministry of Health (DGOS) provided national data and methodological support.

Sample

All of the acute care hospitals and acute care hospital multi-activities in France listed in the four national databases for the year 2012 were included. We only excluded hospitals when psychiatry care, follow-up care and rehabilitation or long term care were their only activity, because these are hospitals that provide very specific services. This selection only resulted in exclusion of three hospitals. Moreover, the acute care hospitals and acute care hospital multi-activities represented about $79 \%$ of all French hospitals in $2012^{1}$. The criteria for retention can hence be considered to be representative of the French health system. In total, 1,007 hospitals met the inclusion criteria ${ }^{2}$ and constituted our initial sample but hospitals with a lot of missing data, particularly for the key variables (EHR adoption, HIT development, etc.), were excluded from the analysis. It is the main reason for the decrease in sample size in our models. All of the variables are listed in Table 1 and Table 2.

\section{Variables}

\section{Bed occupancy rates in surgical units (dependent variables)}

The bed occupancy rates in surgical inpatient units (model 1 and 1bis) and bed occupancy rates in surgical outpatient units (model 2 and 2bis) were extracted from the Hospi-Diag database. The bed occupancy rates in surgical inpatient units were calculated as follows: number of days registered in the surgical unit divided by the total number of beds available in the surgery. Therefore, the surgical stays registered throughout hospital, and not only the stays registered in a particular surgical bed, were considered ${ }^{3}$.

The bed occupancy rates in surgical outpatient units were calculated as follows: number of stays for one day registered in the surgical unit divided by the total number of beds available in the outpatient surgical unit *220).

These two dependent variables reflect the hospitals' organization, and more precisely, the efficiency of the surgical unit. Higher bed occupancy rates reflect better utilization and management of resources. The rates of surgical care procedures at inpatient and outpatient units in French hospitals during $2012^{5}$ were $59.2 \%$ and $40.8 \%$, respectively.

\footnotetext{
${ }^{1} \mathrm{http} / / /$ www.insee.fr/fr/themes/tableau.asp?reg_id=0\&ref_id=nattef06116.

${ }^{2}$ Acute care hospitals and acute care hospitals multi-activities in France were listed in the four national databases for the year 2012.

${ }^{3}$ For this reason, we have rates that exceed $100 \%$.

4220 is the number of "working" days in the surgical outpatient unit after subtracting Saturdays, Sundays, and public holidays.

${ }^{5}$ http://goo.gl/zzy6N6.
} 
Explanatory variables

Two categories of variables and indicators associated with HIT development were used in our models. The specific variables regarding EHR adoption (in all models) are:

- EHR adoption was measured as a quantitative variable, i.e. the percentage of health records that were completely or partially computerized ${ }^{1}$ divided by the total number of health records. This variable was built from the IPAQSS database. Only data from the inpatient unit (model 1 and 1bis) were collected.

- Five binary variables from the oSIS ${ }^{2}$ database were used for model 2 and 2bis (outpatient unit). All of these variables are listed in Table 1.

To examine in detail the effect of EHRs, we could not use the same indicators for inpatient and outpatient units. The variables used to model the surgical inpatient units (model 1 and 1bis) were obtained from the IPAQSS database, which only recorded hospital stays of more than two days. We used four indicators $^{3}$ extracted from the oSIS database to model the outpatient units. These were declarative variables that described all of the possible types of hospital stays. For the analysis concerning the surgical inpatient unit (models 1 and 1bis), use of the IPAQSS database was preferred because it is an objective controlled variable but we also estimated the models for inpatient units with oSIS database. Lastly, in order to be more inclusive of the hospitals that do not adopt EHR, we extended our analysis for inpatient units by including a binary specification of EHR (EHR/nonEHR) that was based on the IPAQSS database. We retained and presented the better specifications in the Results section. Several variables and indicators about HIT were used in our models (models 1 bis and 2bis):

- The first indicator (development of HIT) takes into account the number of microcomputers, mobile computers, tablet computers and any other touch-screen equipment.

- The second indicator (connected equipment) takes into account the amount of connected information technology equipment (number of computers connected to the system and number of Wi-Fi hubs).

These two indicators assess the level of HIT development through the equipment available in the hospital.

- The third indicator (eligibility score) was determined using 12 binary variables $^{4}$ to determine whether a hospital had reached fixed

\footnotetext{
${ }^{1}$ These records were randomized drawn among stays $>2$ days during the second semester 2011 to evaluate the level of computerization.

${ }^{2}$ EHR 1, EHR 2, EHR 3, EHR 4, and EHR 5 (Table 1).

${ }^{3}$ We did not use EHR 2 as a binary indicator because there were too few observations in each category (Tables 1 and 2).

${ }^{4}$ The DGOS defined 12 indicators, called "prerequisite indicators", which are the same for all hospitals and are associated with a target level for computerization.
} 
computerization objectives. The higher the score, the higher the level of computerization of domains deemed important. This score concerns three domains: the patient identity (4 indicators), the data reliability (3 indicators) and data confidentiality (5 indicators) $)^{1}$.

Also included in the models were variables about hospital features: type of hospital (teaching, private non-profit, private for-profit, or other public hospital), total number of surgical beds, total number of different sites, and geographic region; hospital activities: accuracy of care (with versus without home care hospitalization), proportion of oncology in total activity, and percentage of stays in teaching hospitals (partially reflecting the level of technical care); and about patient features: number of stays with a high level of disease severity (3 and 4). This last variable, percentage of stays with a high severity level, could serve as a proxy for the length of stay in the hospital ${ }^{2}$.

Baillie et al. (1997) found that the bed occupancy rate alone did not necessarily represent the efficiency of hospital resource usage of beds because of the length of stay. More precisely, it is possible to find a high occupancy rate and conclude that the hospital was efficiently treating numerous patients, when in fact, the hospitals treated fewer patients who had a longer length of stay. Therefore, it is important to control for this effect to make proper conclusions about the efficiency.

\section{Statistical Analysis}

Descriptive statistics were used to describe the hospital samples. We used the independent samples t-test to assess the relationship between bed occupancy rates and different variables related to EHR adoption or HIT development (Table 2).

The ordinary least squares method was used to evaluate the association between EHR adoption, HIT development, and bed occupancy rates in surgical care units, controlling for several hospital and patient characteristics. Our models were built as follows (Greene 2012):

$$
Y_{j}=\beta_{0}+\beta_{i j} X_{i j}+u_{j}
$$

where $Y$ represents the performance criteria (bed occupancy rate in surgical inpatient or outpatient unit), $X$ is a vector of hospital characteristics (type of hospital, type of activity, total number of beds, geographic regions, etc.) and HIT characteristics (development of HIT connected equipment, eligibility score and EHR), $\beta$ the unknown parameters reflecting their impact, and $u$ the error term following a normal distribution.

\footnotetext{
${ }^{1}$ http://goo.gl/T3KOXT.

${ }^{2}$ The level of severity was defined from the co-morbidity associated with the disease, patient age, and minimum duration of stay (a higher severity level is associated with a longer stay).
} 
Vol. 3, No. $1 \quad$ Plantier et al.: Impact of Electronic Health Records on the Hospital ...

Table 1. Description of the Variables Used in the Models and the Total Number of Observations

\begin{tabular}{|c|c|c|c|}
\hline Variable & Description & Obs. & Mean \\
\hline EHR (only inpatient units) $^{1}$ & $\begin{array}{c}\text { Quantitative variable (QV); number of computerized (totally or partially) patient } \\
\text { records/total patient records }\end{array}$ & 996 & $71.80 \%$ \\
\hline EHR 1 & $\begin{array}{c}\text { Binary variable }(\mathrm{BV})=1 \text { if the record was compatible with system (412 } \\
\text { observations) }\end{array}$ & \multicolumn{2}{|c|}{$\begin{array}{l}137 \text { hospitals achieved this } \\
\text { objective }\end{array}$} \\
\hline EHR 2 & $\mathrm{BV}=1$ if $98 \%^{2}$ of the hospital reports were computerized (411 observations) & \multicolumn{2}{|c|}{9 hospitals achieved this objective ${ }^{3}$} \\
\hline EHR 3 & $\mathrm{BV}=1$ if at least $60 \%$ of the care units used EHRs (412 observations) & \multicolumn{2}{|c|}{$\begin{array}{l}139 \text { hospitals achieved this } \\
\text { objective }\end{array}$} \\
\hline EHR 4 & $\mathrm{BV}=1$ if $95 \%$ of stays had an EHR update (412 observations) & \multicolumn{2}{|c|}{89 hospitals achieved this objective } \\
\hline EHR 5 & $\mathrm{BV}=1$ if $80 \%$ of external consultations had an EHR update (412 observations) & \multicolumn{2}{|c|}{61 hospitals achieved this objective } \\
\hline Development of HIT & $\begin{array}{c}\text { QV; number of microcomputers, computers, tablet computers, and other touch } \\
\text { devices available in hospital }\end{array}$ & 533 & 470.2 \\
\hline Connected equipment & $\begin{array}{c}\text { QV; number of computers connected to the system and number of Wi-Fi hubs } \\
\text { available in hospital }\end{array}$ & 529 & 86.5 \\
\hline Eligibility score & QV; number of objectives achieved/12 domains selected & 412 & 6.14 \\
\hline \multicolumn{4}{|l|}{ Bed occupancy rates } \\
\hline Surgical units (inpatient) & $\begin{array}{c}\text { QV; number of days registered in surgical inpatient unit/total number of beds } \\
\text { available in surgical inpatient unit }\end{array}$ & 905 & 65.24 \\
\hline Surgical units (outpatient) & $\begin{array}{c}\text { QV; number of stays in surgical outpatient unit/(total number of beds available } \\
\text { in outpatient surgical unit * 220) }\end{array}$ & 913 & 92.45 \\
\hline
\end{tabular}

\footnotetext{
${ }^{1}$ This indicator is not calculated based on the outpatient unit because it is based on information from health records of stays longer than 2 days.

${ }^{2}$ The thresholds for EHR 2, 3, 4 and 5 were defined by the DGOS, and these are the same for all hospitals.

${ }^{3} \mathrm{We}$ did not include this variable in our model because of the low number of observations in the category "hospitals achieved this objective". Only 9 hospitals were in this category (less than $5 \%$ of the total number). To use a binary variable in econometric model, we must have at least $5 \%$ of the total number of observations in each category.
} 


\begin{tabular}{|c|c|c|c|}
\hline Hospital characteristics & & & \\
\hline Private for-profit & $\mathrm{BV}=1$ if private for-profit hospital (1,007 observations) & \multicolumn{2}{|c|}{434 private for-profit hospitals } \\
\hline Private non-profit & $\mathrm{BV}=1$ if private non-profit hospital (1,007 observations) & \multicolumn{2}{|c|}{92 private non-profit hospitals } \\
\hline Teaching & $\mathrm{BV}=1$ if teaching hospital or cancer center $(1,007$ observations $)$ & \multicolumn{2}{|c|}{56 teaching hospitals } \\
\hline Other public & $\mathrm{BV}=1$ if public hospital (except teaching hospital or cancer center; 1,007 & \multicolumn{2}{|c|}{425 public hospitals } \\
\hline Acute care only & $\mathrm{BV}=1$ if acute care is the sole activity $(1,007$ observations $)$ & \multicolumn{2}{|c|}{$\begin{array}{l}369 \text { hospitals that only practice } \\
\text { acute care }\end{array}$} \\
\hline $\begin{array}{l}\text { With home care } \\
\text { hospitalization }\end{array}$ & $\begin{array}{l}\mathrm{BV}=1 \text { if acute care hospital with multi-activities, with home care hospitalization } \\
\text { (1,007 observations) }\end{array}$ & \multicolumn{2}{|c|}{$\begin{array}{l}121 \text { acute care hospitals with home } \\
\text { care hospitalization }\end{array}$} \\
\hline $\begin{array}{c}\text { Without home care } \\
\text { hospitalization }\end{array}$ & $\begin{array}{c}\mathrm{BV}=1 \text { if acute care hospital with multi-activities, without home care } \\
\text { hospitalization (1,007 observations) }\end{array}$ & \multicolumn{2}{|c|}{$\begin{array}{l}517 \text { acute care hospitals without } \\
\text { home care hospitalization }\end{array}$} \\
\hline $\begin{array}{l}\text { Percentage of oncology } \\
\text { stays }\end{array}$ & QV; number of stays in oncology unit/total number of stays & 1,236 & 13.01 \\
\hline $\begin{array}{l}\text { Percentage of stays } \\
\text { supported mainly by } \\
\text { teaching hospitals }\end{array}$ & $\begin{array}{c}\text { QV; number of stays supported in major part by teaching hospital/total number } \\
\text { of stays } \\
\text { (stays in second line) }\end{array}$ & 1,236 & 1.19 \\
\hline $\begin{array}{l}\text { Percentage of stays with a } \\
\text { higher level of severity }\end{array}$ & QV; number of stays with a higher level of severity/total number of stays & 1,236 & 9.93 \\
\hline Number of inpatient beds & QV; number of inpatient beds available in surgical unit & 921 & 90.66 \\
\hline Number of outpatient beds & QV; number of outpatient beds available in surgical unit & 929 & 16.46 \\
\hline Number of sites & QV; number of sites where the hospital is set up & 1,007 & 1.26 \\
\hline
\end{tabular}

Source: Authors' estimations.

Notes: EHR=Electronic health records; Obs.=observations; HIT=Health information technology. 
We determined the relationship between the bed occupancy rates in surgical inpatient or outpatient units and the implementation of EHRs (models 1 and 2). We refined these analyses by adding other variables associated with HIT development (models 1 bis and 2bis). All statistical analyses were performed using STATA ${ }^{\circledR}$ software (version 13.0).

\section{Results}

We noted that HIT development was heterogeneous among the different French hospitals; we observed this difference from the oSIS national database, which included the utilization rate of the various informatics materials.

Table 2 lists the descriptive statistics (independent samples t-tests) and reports the equivalent or best bed occupancy rates in surgical inpatient units that made an effort to adopt EHR or develop HIT. We found that hospitals had a better bed occupancy rate, on average, when at least $60 \%$ of the care units used EHRs (EHR 3; p=0.001). In outpatient units, the results varied. For example, the mean bed occupancy rates in surgical outpatient units in hospitals with $<174$ pieces of computer equipment ${ }^{1}$ were better than the bed occupancy rates in hospitals with $>174$ pieces of computer equipment $(p<0.001)$. These differences revealed that it was necessary to complete the analysis with econometric modeling to control for the various characteristics.

Of the 739 hospitals included in model 1 (Table 3), 156 hospitals had $<10 \%$ of their records computerized, and 286 had all of their records at least partially computerized. This disparity could explain the differences we observed in the bed occupancy rates in the surgical inpatient units. Table 3 reports the results of the multivariate linear regression for model 1 , revealing that, after controlling for the type of hospital, type of activity, and patient characteristics, hospitals that adopted EHRs had higher bed occupancy rates in surgical inpatient units $(p=0.002)$. The second model for bed occupancy rates in surgical inpatient units (model 1bis), presented in Table 4, confirmed this result ( $\mathrm{p}=0.013)$. This model also demonstrated that HIT development was important, although it was not associated with the bed occupancy rates. Taken together, EHRs seem to be a key variable of HIT, which improve bed occupancy rates in surgical inpatient units. Moreover, model 1 illustrates that hospitals with larger surgical inpatient units (with a high number of surgical beds) had the best bed occupancy rates $(\mathrm{p}=0.038)$. By contrast, private for-profit hospitals $(\mathrm{p}=0.005)$ and private nonprofit hospitals $(\mathrm{p}=0.047)$ were associated with lower bed occupancy rates in surgical inpatient units. However, these results were not confirmed with model 1bis. Finally, the characteristic that most influenced the bed occupancy rates in both models was the percentage of stays with a higher level of severity $(\mathrm{p}<0.001$, $\mathrm{p}=0.001$ for model 1 and model 1bis, respectively). More precisely, hospitals that had a larger percentage of severe cases had higher bed occupancy rates in their surgical units. This confirms the hypothesis that longer stays have a positive impact on the bed occupancy rate.

\footnotetext{
${ }^{1} 174$ is the median of the variable "development of HIT".
} 
Table 2. Bed Occupancy Rates in Surgical Inpatient Units and Surgical Outpatient Units and Implementation of EHRs and HIT

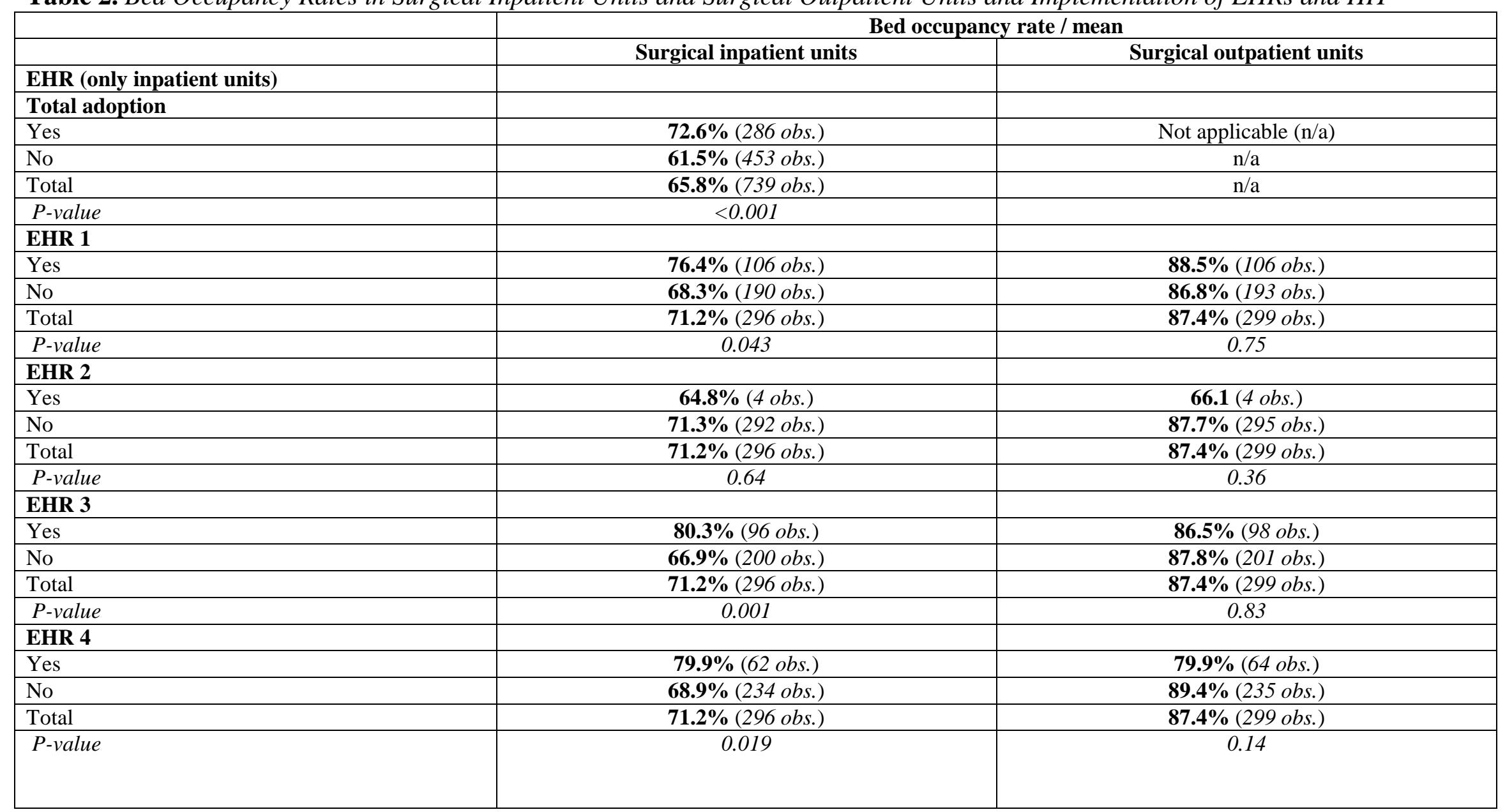


Vol. 3, No. 1 Plantier et al.: Impact of Electronic Health Records on the Hospital ...

\begin{tabular}{|c|c|c|}
\hline EHR 5 & & \\
\hline Yes & 81.1\% (46 obs.) & 83.3\% (48 obs.) \\
\hline No & 69.4\% (250 obs.) & $\mathbf{8 8 . 2 \%}$ (251 obs.) \\
\hline Total & 71.2\% (296 obs.) & 87.4\% (299 obs.) \\
\hline$P$-value & 0.028 & 0.508 \\
\hline \multicolumn{3}{|c|}{ Score EHR } \\
\hline 0 & $\mathbf{6 4 . 8 \%}$ (144 obs.) & $\mathbf{8 6 . 3 \%}$ (145 obs.) \\
\hline$\geq 1$ & 77.3\% (152 obs.) & 88.5\% (154 obs.) \\
\hline Total & 71.2\% (296 obs.) & 87.4\% (299 obs.) \\
\hline$P$-value & 0.001 & 0.50 \\
\hline \multicolumn{3}{|c|}{ Development of HIT } \\
\hline$<174$ & $\mathbf{5 5 . 7 \%}$ (169 obs.) & 100.1\% (181 obs.) \\
\hline$\geq 174$ & $\mathbf{7 8 . 8 \%}$ (225 obs.) & 79.4\% (218 obs.) \\
\hline Total & 68.9\% (394 obs.) & 88.8\% (399 obs.) \\
\hline$P$-value & $<0.001$ & $<0.001$ \\
\hline \multicolumn{3}{|c|}{ Connected equipment } \\
\hline$<33$ & $\mathbf{5 7 . 4 \%}$ (157 obs.) & 95.7\% (167 obs.) \\
\hline$\geq 33$ & 76.3\% (230 obs.) & 83.8\% (225 obs.) \\
\hline Total & 68.6\% (387 obs.) & 88.9\% (392 obs.) \\
\hline$P$-value & $<0.001$ & 0.022 \\
\hline \multicolumn{3}{|c|}{ Eligibility score } \\
\hline$<7$ & 70.7\% (143 obs.) & 82.2\% (146 obs.) \\
\hline$\geq 7$ & 71.7\% (153 obs.) & 92.4\% (153 obs.) \\
\hline Total & 71.2\% (296 obs.) & 87.4\% (299 obs.) \\
\hline$P$-value & $<0.001$ & 0.060 \\
\hline
\end{tabular}

Source: Authors' estimations.

Notes: EHR=Electronic health records; Obs.=observations; HIT=Health information technology. The mean of the bed occupancy rates in surgical inpatient units was $55.7 \%$ for the hospitals with a "development of HIT" $<174$ (169 hospitals), whereas it was 78.8\% for the hospitals with a "development of HIT" $\geq 174$ (225 hospitals); it was $68.9 \%$ for all hospitals (394 hospitals). The limit values retained for "connected equipment", "Development of HIT", "Eligibility score", and

"Score EHR" are the median of these variables. 
For surgical outpatient units, model 2 (Table 3) revealed that hospitals had a better bed occupancy rate when at least $60 \%$ of the care units used EHRs $(\mathrm{p}=0.024)$. The other indicators associated with EHR adoption were not associated with bed occupancy rates in the surgical outpatient units. This was also confirmed with the second model, model 2 bis in Table $4(\mathrm{p}=0.061)$, which also demonstrated the positive impact of the number of items of computer equipment available in the hospital $(\mathrm{p}=0.001)$. Private for-profit $(\mathrm{p}<0.001$, $\mathrm{p}<0.001$ for model 2 and 2bis, respectively) and teaching ( $<<0.001, \mathrm{p}=0.009$ for model 2 and 2bis, respectively) hospitals also had better bed occupancy rates in surgical outpatient units, whereas hospitals with larger surgical outpatient units had lower bed occupancy rates $(\mathrm{p}<0.001, \mathrm{p}<0.001$ for model 2 and 2 bis, respectively) in both models.

Table 3. Multivariate Linear Model Estimates of the Association Between the Bed Occupancy Rates in Surgical Inpatient Units (Model 1) and Surgical Outpatient Units (Model 2) and EHR Adoption

\begin{tabular}{|c|c|c|c|c|}
\hline \multirow[b]{2}{*}{ Variable } & \multicolumn{2}{|c|}{ Model 1 } & \multicolumn{2}{|l|}{ Model 2} \\
\hline & $\begin{array}{c}\text { Bed occupancy } \\
\text { rate } \\
\text { (inpatient units) }\end{array}$ & $p$-value & $\begin{array}{c}\text { Bed occupancy } \\
\text { rate } \\
\text { (outpatient units) }\end{array}$ & $p$-value \\
\hline EHR (inpatient units) & 7.09 & 0.002 & - & - \\
\hline EHR 1 & - & - & 2.00 & 0.716 \\
\hline EHR 3 & - & - & 15.85 & 0.024 \\
\hline EHR 4 & - & - & -7.19 & 0.389 \\
\hline EHR 5 & - & - & 1.94 & 0.825 \\
\hline Number of surgical outpatient beds & - & - & -1.49 & 0.000 \\
\hline Number of surgical inpatient beds & 0.03 & 0.038 & - & - \\
\hline Number of sites & 1.52 & 0.090 & -7.68 & 0.500 \\
\hline Private for-profit hospital & -10.75 & 0.005 & 46.46 & 0.000 \\
\hline Teaching hospital & -7.01 & 0.349 & 77.85 & 0.000 \\
\hline Private non-profit hospital & -9.11 & 0.047 & 13.87 & 0.265 \\
\hline Acute care (only) & -4.69 & 0.071 & 12.75 & 0.082 \\
\hline $\begin{array}{l}\text { Acute care hospital with home care } \\
\text { hospitalization }\end{array}$ & 1.53 & 0.589 & 10.73 & 0.113 \\
\hline Rhône-Alpes Auvergne & 3.65 & 0.294 & -2.40 & 0.852 \\
\hline West & 9.55 & 0.004 & 2.54 & 0.840 \\
\hline East & 1.39 & 0.692 & 22.09 & 0.086 \\
\hline North & -0.67 & 0.838 & 19.83 & 0.118 \\
\hline Southeast & 2.14 & 0.504 & -1.74 & 0.892 \\
\hline Southwest & 7.04 & 0.034 & 6.18 & 0.616 \\
\hline $\begin{array}{l}\text { Percentage of stays supported mainly } \\
\text { by teaching hospitals }\end{array}$ & 0.76 & 0.106 & -1.37 & 0.513 \\
\hline $\begin{array}{l}\text { Percentage of stays with a higher level } \\
\text { of severity }\end{array}$ & 1.55 & 0.000 & - & - \\
\hline Percentage of oncology stays & -0.07 & 0.505 & -0.96 & 0.000 \\
\hline \multirow[t]{2}{*}{ Constant } & 51.86 & 0.000 & 88.92 & 0.000 \\
\hline & \multicolumn{2}{|c|}{ Obs.: $739 \mathrm{R}^{2}: 28.6 \%$} & \multicolumn{2}{|c|}{ Obs.: $299 \mathrm{R}^{2}: 23.9 \%$} \\
\hline
\end{tabular}

Source: Authors' estimations.

Note: $\mathrm{EHR}=$ Electronic health record. 
Vol. 3, No. 1 Plantier et al.: Impact of Electronic Health Records on the Hospital ...

Table 4. Multivariate Linear Model Estimates of the Association between the Bed Occupancy Rates in Surgical Inpatient Units (Model 1bis) and Surgical Outpatient Units (Model 2bis) and HIT Development

\begin{tabular}{|c|c|c|c|c|}
\hline \multirow[b]{2}{*}{ Variable } & \multicolumn{2}{|c|}{ Model 1bis } & \multicolumn{2}{|c|}{ Model 2bis } \\
\hline & $\begin{array}{c}\text { Bed occupancy } \\
\text { rate } \\
\text { (inpatient units) }\end{array}$ & $p$-value & $\begin{array}{l}\text { Bed occupancy } \\
\text { rate } \\
\text { (outpatient units) }\end{array}$ & $p$-value \\
\hline EHR (inpatient units) & 12.69 & 0.013 & - & - \\
\hline EHR 1 & - & - & 2.68 & 0.639 \\
\hline EHR 3 & - & - & 13.28 & 0.061 \\
\hline EHR 4 & - & - & -6.17 & 0.455 \\
\hline EHR 5 & - & - & -1.07 & 0.904 \\
\hline Development of HIT & 0.002 & 0.454 & 0.01 & 0.001 \\
\hline Connected equipment & 0.01 & 0.162 & -0.003 & 0.763 \\
\hline Eligibility score & 0.26 & 0.642 & 0.46 & 0.567 \\
\hline Number of surgical outpatient beds & - & - & -1.62 & 0.000 \\
\hline Number of surgical inpatient beds & -0.05 & 0.241 & - & - \\
\hline Number of sites & -6.26 & 0.449 & -6.05 & 0.588 \\
\hline Private for-profit hospital & 6.91 & 0.415 & 52.78 & 0.000 \\
\hline Teaching hospital & -8.26 & 0.572 & 47.99 & 0.009 \\
\hline Private non-profit hospital & 3.26 & 0.744 & 18.85 & 0.129 \\
\hline Acute care (only) & -6.38 & 0.254 & 11.87 & 0.100 \\
\hline $\begin{array}{l}\text { Acute care hospital with home care } \\
\text { hospitalization }\end{array}$ & -4.81 & 0.346 & 12.00 & 0.078 \\
\hline Rhone-Alpes Auvergne & 11.50 & 0.244 & 7.28 & 0.579 \\
\hline West & 17.16 & 0.070 & 13.65 & 0.290 \\
\hline East & 6.44 & 0.509 & 32.10 & 0.015 \\
\hline North & 4.51 & 0.636 & 28.09 & 0.029 \\
\hline Southeast & 6.52 & 0.499 & 9.71 & 0.457 \\
\hline Southwest & 6.66 & 0.478 & 14.03 & 0.268 \\
\hline $\begin{array}{l}\text { Percentage of stays supported } \\
\text { mainly by teaching hospitals }\end{array}$ & 3.12 & 0.041 & -3.87 & 0.077 \\
\hline $\begin{array}{l}\text { Percentage of stays with a higher } \\
\text { level of severity }\end{array}$ & 3.00 & 0.001 & - & - \\
\hline Percentage of oncology stays & -0.11 & 0.594 & -0.59 & 0.031 \\
\hline Constant & 36.75 & 0.017 & 68.42 & 0.000 \\
\hline & Obs.: $284 \mathrm{R}^{2}$ : & $7.99 \%$ & Obs.: $287 \mathrm{R}^{2}: 2$ & $6.4 \%$ \\
\hline
\end{tabular}

Source: Authors' estimations.

Notes: EHR=Electronic health record; HIT=Health information technology.

\section{Discussion}

This study presents some of the results from a global research project called e-SI. This research assessed the impact of the development of HIT on health systems, and - more precisely - its impact on consultation, home care hospitalization, strategic decision-making, and hospital performance. The study presented here is a part of this last objective, which includes the impact on quality, performance, organization and financial data, and particularly the impact of HIT on the bed occupancy rates in surgical units in French hospitals. 
Our findings suggest that the implementation of EHRs is associated with higher bed occupancy rates in surgical units; HIT development also has a positive impact on these rates in outpatient units. To complete the analysis of the effect of EHRs, we built a composite score based on the five binary variables extracted from the oSIS database (EHR 1-5) ${ }^{1}$. The association between the bed occupancy rates in surgical outpatient units and EHRs was confirmed using this score $(\mathrm{p}=0.046)$. The model and its details were used (model 2) to examine this relationship. We found that it was specifically the number of care units using EHRs that had a large impact on the bed occupancy rates. Therefore, widespread adoption of EHRs would have the most impact on bed occupancy rates in hospitals. Model 2bis further demonstrated that the higher the number of microcomputers, computers, tablet computers, and other touch-screen devices available, the higher the bed occupancy rates in surgical outpatient units. Therefore, surgical outpatient units should increase the number of care units with complete EHR implementation and the number of items of computer equipment available. We can suppose that these elements allow better communication between care units and medical staff and consequently better resource utilization, in particular of beds.

For the analysis concerning the surgical inpatient unit (models 1 and 1bis), we estimated a linear model for units using a composite score based on five variables (EHR 1-5) from the oSIS database (declarative variables); this model confirmed the relationship between these measures $(p=0.09)$. We also estimated the models for inpatient units with details of four indicators from the oSIS database (such as models 2 and 2bis). These models confirmed the results about the EHR indicator (IPAQSS), but reduced the sample size and quality ${ }^{2}$ of the models, compared to the models without the variables, while the added variables were not significant. We hence retained the models without these variables (models 1 and 1bis). We assessed other models for inpatient units with the last specification including a binary variable about EHR (EHR/nonEHR), based on the IPAQSS database, to replace the percentage of computerized (total or partial) patient records. The first model, with only this variable associated with HIT, confirmed the positive association between EHR adoption and the bed occupancy rate in surgical inpatient units $(p=0.027)$, although it did slightly reduce the quality of the model compared model 1 . The second model, with other variables relating to HIT, demonstrated independence between EHR adoption and the bed occupancy rate, although it also reduced the quality compared to model 1 bis. We hence retained models 1 and 1 bis. Lastly, when we compared the two models which were retained in this paper (model 1 and 1bis), different results regarding the impact of hospital characteristics can be seen. However, considering the way these models were constructed, and their quality, with the adjusted R-squared, we conclude that model 1 is most appropriate. When we added three variables in model $1 \mathrm{bis}$, it reduced the sample size and quality, compared to model 1, while the added

\footnotetext{
${ }^{1}$ We added the five binary variables to obtain a five-point score: each point indicates increasingly complete EHRs.

${ }^{2}$ Adjusted R-squared.
} 
variables were not significant. Hence, to improve bed occupancy rates in surgical inpatient units, only the EHRs seems to be pertinent among the variables relating to HIT development.

Our empirical models controlled for the effects of hospital features. Dormont and Milcent (2012) showed the importance of these variables regarding the care production level. For example, because they have different objectives and regulations, public and private hospitals have different levels of care production, in favor of private hospitals. Private care hospitals can choose their care activities and patients, allowing them, in theory, to achieve the best level of care production. However, previous models that controlled for the effects of hospital size, activity, and patient features demonstrated the opposite result. Our finding confirmed the impact that the types of hospital, type of activity, and patient characteristics have on hospital performances. More precisely, we saw an important association between the percentage of stays with a higher level of severity and bed occupancy rates in surgical inpatient units ${ }^{1}$. Baillie et al. (1997) demonstrated that the length of stay can increase the bed occupancy rate without affecting better resource utilization. Indeed, a long hospital stay can result from a long bed occupation without more patients being treated. We assume that stays where patients had a higher level of severity are, on average, longer, which explains this positive impact. Therefore, the reason for the hospital stay is a key variable of hospital performance.

Overall, the strength of this study can be summed up by these three points: it is multi-center study, with an original method, which included innovative indicators and was characterized by the use of national and objective databases. The limitations of this study come from the missing data and, more precisely, from the bias related to those missing data. To correct these limitations we suggest the implementation of an appropriate method, and above all, to conduct the same analyses on data from years 2015 and 2016, which are more complete.

\section{Conclusions}

In conclusion, our results suggest that to achieve better utilization of beds in surgical units, hospitals should adopt a complete EHR system, i.e. have all records computerized across all units. These conclusions are based on an innovative method using unique HIT indicators. Indeed, these indicators provided an overview of EHR adoption and, more generally, of HIT development in French hospitals using the oSIS and IPAQSS databases. The variables within these databases provided a new description of the implementation of HIT in French hospitals.

Overall, the implementation of EHRs seems to be the key variable from HIT to increase bed occupancy rates in all models estimated and with the

\footnotetext{
${ }^{1}$ We did not include this variable in our models for surgical outpatient units because this category of stays was not relevant for this unit.
} 
different variables tested. Other studies have shown its potential to improve the quality of care (Jarvis et al. 2013), safety of care (less medical errors) (Huckvale et al. 2010), and patient satisfaction (Irani et al. 2009). Therefore, we believe that global adoption of EHRs will lead to better hospital efficiency.

\section{Acknowledgments}

The authors are grateful to the French Ministry of Health (DGOS), French National Authority for Health (HAS), and French National Agency of Hospital Performances (ANAP) for access to the national databases and their support in conducting this study. The study received financial and research support from the DGOS (Programme de recherche sur la performance du système de soins: Evaluation de la création de valeur par l'usage des SI de production de soins (PREPS-SIPS)).

\section{References}

Baillie H, Wright W, McLeod A, Craig N, Leyland A, Drummond N, Boddy A (1997) Bed Occupancy and Bed Management. Report of CSO Project K/OPR/2/2/D248. University of Glasgow, Public Health Research Unit.

Bassi J, and Lau F (2013) Measuring value for money: a scoping review on economic evaluation of health information systems. Journal of the American Medical Informatics Association 20: 792-801.

Black AD, Car J, Pagliari C, Anandan C, Cresswell K, Bokun T, McKinstry B, Procter R (2011) The impact of eHealth on the quality and safety of health care: a systematic overview. PLoS Medicine 8(1). DOI: 10.1371/journal.pmed.1000387

Chaudhry B, Wang J, Wu S, Maglione M, Mojica W, Roth E, Morton SC, Shekelle PG (2006) Systematic review: impact of health information technology on quality, efficiency, and costs of medical care. Annals of Internal Medicine 144(10): 742-752.

Donald S, Hodgkin D, Anthony YE (2000) Analysis of Hospital Costs: A Manual for Managers. Geneva, Switzerland: World Health Organization, (p. 6-52).

Dormont B, Milcent C (2012) How to evaluate the productivity efficiency of public and private hospitals? The issues of price convergence. Economie et Statistique 455-456.

Greene WH (2012) Econometric Analysis, $7^{\text {th }}$ edn., Stern School of Business, NewYork University.

Hillestad R, Bigelow J, Bower A, Girosi F, Meili R, Scoville R, Taylor R (2005) Can electronic medical record systems transform health care? potential health benefits, savings, and costs. Health Affairs 24(5): 1103-1117.

Huckvale C, Car J, Akiyama M, Jaafar S, Khoja T, Bin Khalid A, Sheikh A, Majeed A (2010) Information technology for patient safety. Quality and Safety in Health Care 19(Suppl 2): i25-33.

Irani JS, Middleton JL, Marfatia R, Omana ET, D'Amico F (2009) The use of electronic health records in the exam room and patient satisfaction: a systematic review. Journal of the American Board of Family Medicine 22(5): 553-562. 
Jamal A, McKenzie K, Clark M (2009) The impact of health information technology on the quality of medical and health care: a systematic review. HIM-Health Information Management Journal 38(3): 26-37.

Jarvis B, Johnson T, Butler P, O'Shaughnessy K, Fullam F, Tran L, Gupta R (2013) Assessing the impact of electronic health records as an enabler of hospital quality and patient satisfaction. Academic Medicine 88(10): 1471-1477.

Meyer R, Degoulet P (2008) Assessing the capital efficiency of health care information technologies investments: an econometric perspective. Yearbook of Medical Informatics 114-127.

Michelsen K, Brand H, Achterberg P, Wilkinson J (2015) Promoting Better Integration of Health Information Systems: Best Practices and Challenges. Copenhagen: WHO Regional Office for Europe.

Nguyen L, Bellucci E, Nguyen LT (2014) Electronic health records implementation: an evaluation of information system impact and contingency factors. International Journal of Medical Informatics 83(11): 779-796.

O'Reilly D, Tarride JE, Goeree R, Lokker C, McKibbon KA (2012) The economics of health information technology in medication management: a systematic review of economic evaluations. Journal of the American Medical Informatics Association 19: 423-438.

WHO-World Health Organization (2010) Health Systems Financing: The Path to Universal Coverage. World Health Report. Geneva: Switzerland. 